\title{
Triamcinolone Acetonide affects TGF- $\beta$ signaling regulation of fibrosis in idiopathic carpal tunnel syndrome
}

\author{
Tai-Hua Yang ${ }^{1}$, Anne Gingery', Andrew R. Thoreson ${ }^{1}$, Dirk R. Larson², Chunfeng Zhao ${ }^{1}$ and Peter C. Amadio ${ }^{1,3^{*}}$ (D)
}

\begin{abstract}
Background: Fibroblast behavior and cell-matrix interactions of cells from normal and idiopathic carpal tunnel syndrome (CTS) subsynovial connective tissue (SSCT) with and without Triamcinolone Acetonide (TA) were compared in this study. A cell-seeded gel contraction model was applied to investigate the effect of steroid treatment on SSCT fibroblast gene expression and function.
\end{abstract}

Methods: SSCT cells were obtained from CTS patients and fresh cadavers. Cells were isolated by mechanical and collagenase digestion. Collagen gels $(1 \mathrm{mg} / \mathrm{ml})$ were prepared with SSCT cells $\left(1 \times 10^{6} / \mathrm{mL}\right)$. A sterile Petri dish with a cloning ring in the center was prepared. The area between the ring and outer dish was filled with cell-seeded collagen solution and gelled for $1 \mathrm{~h}$. The gel was released from the outer way of the petri dish to allow gel contraction. Cell seeded gels were treated with $10 \mathrm{M}$ triamcinolone acetonide (TA) or vehicle (DMSO) in modified MEM. Every $4 \mathrm{~h}$ for 3 days the contracting gels were photographed and areas calculated. Duplicate contraction tests were performed with each specimen, and the averages were used in the analyses, which were conducted using two-factor analysis of variance in a generalized linear model framework utilizing generalized estimating equations (GEE) to account for the correlation between samples. The contraction rate was determined by the area change over time, and the decay time constant was calculated. A customized mechanical test system was used to determine gel stiffness and tensile strength. Gene expression was assessed using Human Fibrosis and Cell Motility PCR arrays.

Results: TA-treated gels had a significantly higher contraction rate, tensile strength and stiffness than the untreated gels. Proteinases involved in remodeling had increased expression in TA-treated gels of the patient group. Profibrotic genes and ECM regulators, such as TGF- $\beta$, collagens and integrins, were down-regulated by TA, indicating that TA may work in part by decreasing fibrotic gene expression.

Conclusions: This study showed that TA affects cell-matrix interaction and suppresses fibrotic gene expression in the SSCT cells of CTS patients.

Keywords: Carpal tunnel syndrome, Collagen gel contraction, Fibrosis, Subsynovial connective tissue, Triamcinolone Acetonide

\footnotetext{
* Correspondence: pamadio@mayo.edu

${ }^{1}$ Biomechanics \& Tendon and Soft Tissue Biology Laboratory, Division of

Orthopedic Research, Rochester, USA

${ }^{3}$ Tendon and Soft Tissue Biology Laboratory, Division of Orthopedic

Research, Mayo Clinic, 200 First Street SW, Rochester, MN 55905, USA

Full list of author information is available at the end of the article
}

(c) The Author(s). 2018 Open Access This article is distributed under the terms of the Creative Commons Attribution 4.0 International License (http://creativecommons.org/licenses/by/4.0/), which permits unrestricted use, distribution, and reproduction in any medium, provided you give appropriate credit to the original author(s) and the source, provide a link to the Creative Commons license, and indicate if changes were made. The Creative Commons Public Domain Dedication waiver (http://creativecommons.org/publicdomain/zero/1.0/) applies to the data made available in this article, unless otherwise stated. 


\section{Background}

In the United States, hundreds of thousands of carpal tunnel release (CTR) procedures are performed each year $[1,2]$. Although most cases of carpal tunnel syndrome (CTS) are idiopathic [3, 4], other causes have been reported, such as repetitive motion, congenital anomalies, autoimmune disorders, arthritis and trauma [5-7]. Subsynovial connective tissue (SSCT) fibrosis and vascular proliferation have been reported as significant factors in CTS development $[8,9]$. This fibrosis impedes the normal ulnodorsal motion of the median nerve when the hand is pinching and gripping while the wrist is flexed and may therefore result in nerve compression between the flexor tendons and flexor retinaculum [10-12].

Surgical decompression is the most common treatment of moderate to severe CTS [13]. However, non-surgical treatments, such as anti-inflammatory medication, corticosteroid injection, immobilization and physical therapy, are often used in milder cases [14-16]. Steroid injection was first described by Kendrick in 1957 [17]. Subsequent studies have reported a wide range of success rates, from 50 to $90 \%$ at $4-12$ weeks and less at longer time points $[14,15]$.

One concern about the effectiveness of corticosteroid therapy for CTS is that these drugs are normally used for their anti-inflammatory effect, whereas the fibrosis in CTS is typically non-inflammatory $[8,11]$. Therefore, the mechanism by which local steroid injection affects CTS remains unknown.

In this study, our hypothesis was that steroid treatment reduces TGF- $\beta$-related fibrosis activation and SSCT fibroblast activity. Both mechanical and molecular biology approaches were used to examine differences in SSCT fibroblast behavior and collagen interactions between cells from normal tissue and cells from idiopathic CTS tissue, with and without steroid, i.e., Triamcinolone Acetonide (TA), treatment. We chose TA because it is commonly injected clinically to treat CTS $[16,18]$.

\section{Methods}

\section{Study design}

We used a gel contraction model as a measure of SSCT fibroblast activation, based on the rate of collagen gel contraction and the change of the contracted gel's mechanical and temporal contraction properties as previously described [19]. Molecular assays of gene expression and an assay of collagen degradation products in the conditioned media were used to investigate the molecular response to TA treatment on TGF- $\beta$ regulation and various molecular markers associated with CTS.

\section{SSCT fibroblast preparation}

SSCT tissue was harvested with our Institutional Review Board's approval. Tissues were harvested from the operated hands of 5 patients with idiopathic CTS, 3 female and 2 male, with a mean age of 58.4 (SD 4.8) years. Tissue was also harvested from the hands of same number fresh cadavers (within $12 \mathrm{~h}$ post mortem) of individuals with no history of CTS, with a mean age of 58.6 (SD 6.9). Patients and cadavers were excluded if they had a history of major trauma, prior steroid injection or surgery for CTS, or hand/wrist pathology, including known tumors/deformities, arthritis or metabolic disorders.

The tissue was harvested with $10 \times 5 \times 1 \mathrm{~mm}$ in size as needed from patients undergoing open carpal tunnel release and minced in minimal essential medium (MEM) with Earle's salts (GIBCO, Grand Island, NY) modified with $10 \%$ fetal bovine serum (GIBCO) and $1 \%$ Antibiotic-Antimycotic (GIBCO). Cells were cultured in $10-\mathrm{cm}$-diameter culture dishes and grown in the same media and supplements at $37{ }^{\circ} \mathrm{C}$, in a $5 \% \mathrm{CO}_{2}$ humidified atmosphere, with the media changed every 3 days. The SSCT cells were passaged at $90 \%$ confluence, and passage 4 cells were used in all experiments.

\section{Cell-seeded collagen gel preparation}

Collagen gels were prepared as previously reported [19]. Briefly, a $1.0 \mathrm{mg} / \mathrm{ml}$ collagen/modified MEM sterile solution was made from $1.88 \mathrm{ml}$ Vitrogen type I bovine dermal collagen (Cohesion Technologies, Palo Alto, CA), $1.2 \mathrm{ml} 5 \mathrm{X}$-modified MEM and $2.92 \mathrm{ml}$ distilled water and maintained at $\mathrm{pH} 7.4 \pm 0.2$ on ice. SSCT cells were seeded at $1.0 \times 10^{6}$ cells $/ \mathrm{ml}$ in a $0.5 \mathrm{mg} / \mathrm{ml}$ collagen $/$ modified MEM solution and mixed into the collagen solution at room temperature. A small sterile cloning ring (8-mm outer diameter, 8-mm height) was attached to the center of each of four $3.5-\mathrm{cm}$ Petri dishes with sterile vacuum grease (Dow Corning Corporation, Midland, MI). Then, the area between the ring and the outer part of each dish was filled with a 2-ml cell-seeded collagen solution and was gelled at $37{ }^{\circ} \mathrm{C}$ in a $5 \% \mathrm{CO}_{2}$ humidified incubator for $1 \mathrm{~h}$. During gelation, two media with modified MEM were prepared: one was supplemented with $10 \mu \mathrm{M}$ TA (Sigma-Aldrich, St. Louis, MO), and the other was a dimethyl sulfoxide (Sigma-Aldrich) vehicle media. To facilitate gel contraction, a scalpel was used to release the gelled solution from the dish's wall after $1 \mathrm{~h}$ of gelation. For each sample, four plates were prepared with $2 \mathrm{ml}$ of media, two with TA-supplemented and two with vehicle media. All experiments were cultured at $37^{\circ} \mathrm{C}$ in a $5 \% \mathrm{CO}_{2}$ humidified incubator with the media changed every $48 \mathrm{~h}$ as per treatment protocol.

\section{Quantification and mechanical testing}

Every $4 \mathrm{~h}$ for 3 days, the contracting gels were photographed and the areas calculated following previously described procedures $[19,20]$. The gel contraction rate was determined by the change over time of the gel contraction 
percentage (the ratio of the current gel surface area over the initial area). Complete gel contraction was determined when gel contracted to less than $5 \%$ of original size. The decay time constant $(B)$, which is directly proportional to the gel contraction rate, was calculated following an established equation (Eq. 1) [19], in which the area data at each time point were modeled with linear regression and optimization to fit an exponential decay function of time. $A_{O}$ is the initial area $(t=0) ; B$ is the decay time constant; and $C$ is the non-zero asymptote as $t \rightarrow \infty$.

$$
A(t)=A_{0} e^{-B t}+C
$$

At the end of day 3, the fully contracted gel ring was taken from the dish. A customized mechanical testing system [19] was used to perform a uniaxial tensile test under displacement control at a $0.5 \mathrm{~mm} / \mathrm{sec}$ distraction rate to determine stiffness and maximal tensile strength. The contracted gel ring was looped around a set of two hooks on the testing machine, which recorded force and displacement data at a sample rate of $10 \mathrm{~Hz}$. The ring was submerged in a room-temperature phosphate-buffered saline (GIBCO) solution to keep the ring moist throughout the test.

\section{PCR Array analyses}

The contracted gel was homogenized with $1 \mathrm{~mL}$ of Trizol reagent (Invitrogen Life Technologies, Grand Island, NY). Total RNA was isolated as previously reported [21]. cDNA was synthesized from equal quantities of total RNA with an iScriptTM cDNA Synthesis Kit (Bio-Rad Laboratories, Inc., Hercules, CA). Gene expressions was measured using Human Fibrosis PCR arrays and Cell Motility PCR arrays (PAHS-120Z and PAHS-128Z, respectively, of SA Biosciences, Frederick, MD) according to the manufacturer's instructions. Fold changes were calculated with a $\log 2$ scale between patient and control tissue, with and without TA treatment. Gene expression analysis was completed using SA Biosciences $\mathrm{RT}^{2}$ Profiler $^{\mathrm{Tm}}$ PCR Array Data Analysis software from The GeneGlobe Data Analysis Center of QIAGEN (https://www.qiagen.com/us/geneglobe).

\section{Quantitative real-time PCR}

In order to confirm array results, select regulated genes from the arrays were analyzed with qRT-PCR (Table 1).
Genes were analyzed in triplicate using the original cDNA, as previously described [22], and values were normalized with TATA binding protein (TBP) as a housekeeping gene. Primers were designed using Primer3web version 4.0.0 software (http://bioinfo.ut.ee/primer3) and purchased from Integrated DNA Technologies (Coralville, IA).

\section{Collagen degradation assessment}

Conditioned media was collected after the first $48 \mathrm{~h}$ and centrifuged at 1500 RPM for $5 \mathrm{~min}$, and the supernatant was collected and stored at $-80{ }^{\circ} \mathrm{C}$. Conditioned media was warmed to room temperature, and CrossLaps ${ }^{\circ}$ for Culture ELISA (Immunodiagnostic Systems, Inc., Fountain Hills, AZ) was used to determine the degradation marker, C-terminal telopeptide of type I collagen, from the breakdown of the contracted cell-seeded gel according to the manufacturer's instructions. Briefly, preparation a two-fold dilution row of the standards, pre-dilution of test specimens with standard diluent and preparation of antibody solution were performed before the test. Then each of standards, control and samples were pipetted into appropriate wells to mix with antibody solution and incubated at room temperature for $2 \mathrm{~h}$. Wash with diluted washing buffer for 5 washing cycles followed by adding substrate solution into each well and incubating for $15 \mathrm{~min}$ at room temperature in the dark on the mixing apparatus. Finally, add stopping solution into each well followed by measuring the absorbance at $450 \mathrm{~nm}$ in an absorbance microplate reader.

\section{Statistical considerations}

The effect of cell type (patient cells or control cells) and treatment type (with TA-supplemented or vehicle media) on the outcomes of decay time constant, tensile strength, stiffness and collagen degradation concentration was analyzed. A total of 10 samples were created from patient and control cells individually (five with TA-supplemented and five with vehicle media for each cell type). Duplicate contraction tests were performed with each specimen, and the averages were used in the analyses, which were conducted using two-factor analysis of variance in a generalized linear model framework utilizing generalized estimating equations (GEE) to account for the correlation between samples. Because significant interactions were observed between cell type and treatment type in the main

Table 1 Primers used in RT-PCR

\begin{tabular}{llll}
\hline Gene & Reference & Forward & Reverse \\
\hline TGF-B1 & NM_000660 & GTGGAAACCCACAACGAAAT & CGGAGCTCTGATGTGTTGAA \\
COL1A2 & NM_0000089 & TCCAAAGGAGAGAGCGGTAA & CAGATCCAGCTTCCCCATTA \\
COL3A1 & NM_000090 & CCAGGAGCTAACGGTCTCAG & CAGGGTTTCCATCTCTTCCA \\
VEGFA & NM_003376 & AGGCCAGCACATAGGAGAGA & TTTCTTGCGCTTTCGTITT \\
TBP & NM_003194 & GGTTGCTGCGGTAATCATGA & CTCCTGTGCACACCATTITCC \\
\hline
\end{tabular}


analysis, additional analyses were performed by generating separate one-factor models to analyze TA's effect separately for patient and control cells. All statistical tests were two-sided and $p$-values less than 0.05 were considered significant.

\section{Results}

\section{Mechanical testing of gel contraction}

Morphologically, in both the control and patient cell types, gels with TA-supplemented media had rough margins after full contraction (Fig. 1). The outcomes organized by factor and by group are shown in Tables 2 and 3, respectively. Regarding the main effects by factor, gels with TA-supplemented media had a significantly higher contraction rate, tensile strength and stiffness than those with vehicle media. Gels seeded with patient cells had a higher contraction rate and stiffness than those seeded with control cells, but no significant difference was observed respecting tensile strength.

Additionally, in individual group comparisons, the gels of control cells with TA-supplemented media had a higher mean contraction rate and mean tensile strength than those with vehicle media. The gels of patient cells with TA-supplemented media also had a higher mean contraction rate and mean tensile strength than those with vehicle media, but the difference was not statistically significant (Fig. 2a and b). The stiffness of the gels with TA-supplemented media was significantly higher than those with vehicle media regardless of cell type (Fig. 2c).

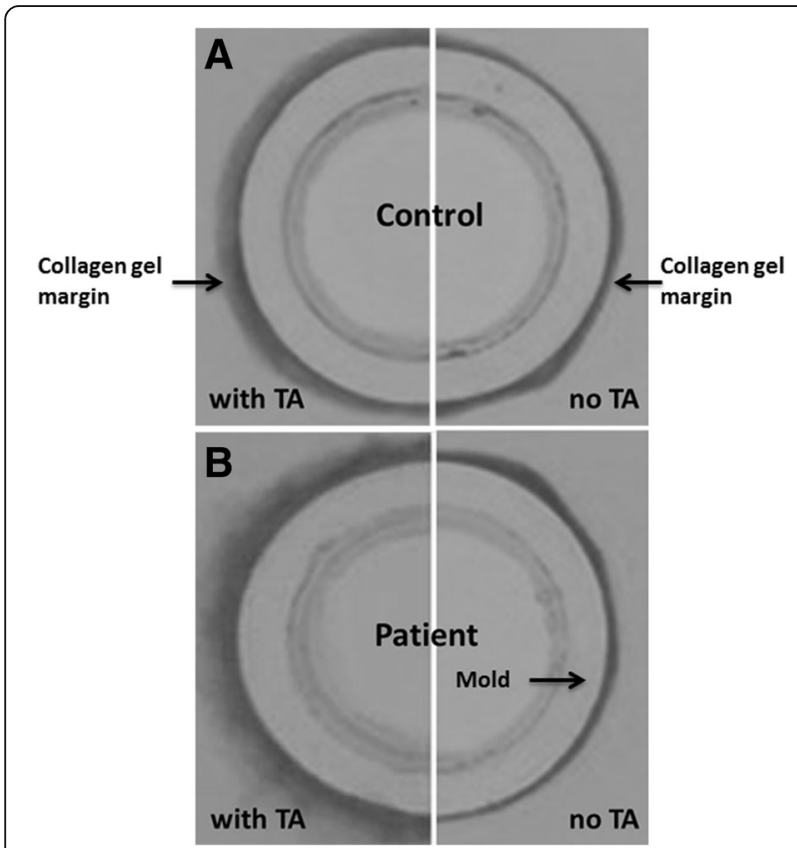

Fig. 1 TA treatment resulted in poorly defined margin formation regardless of cell type. a control, $\mathbf{b}$ patient

\section{PCR Array analyses of fully contracted gels}

In all comparisons, only a twofold or greater up- or down-regulation was considered to represent a changed gene expression. For the Human Fibrosis array (Additional file 1: Table S1), in the gels of patient cells with vehicle media compared to those of control cells with vehicle media, 3 genes were upregulated, e.g., collagen (COL) 3A1, and thrombospondins (THBS) 1 and 2, and 17 were down-regulated, e.g., platelet-derived growth factor (PDGF), vascular endothelial growth factor (VEGF), integrins (ITG) A3 and B6, and matrix metallopeptidase (MMP) 1 (Fig. 3a). In the Cell Motility array (Additional file 2: Table S2), 2 genes were upregulated in the gels of patient cells with vehicle media compared to those of control cells with vehicle media (Fig. 3b). But no down-regulated genes were found.

Regarding TA's effect on gel contraction, in the gels of patient cells with TA-supplemented compared to those with vehicle media, 9 genes in the Human Fibrosis array were upregulated, e.g., tissue inhibitors of metalloproteinase (TIMP) 4, MMP 3 and THBS 1, and 11 were down-regulated, e.g., TGF- $\beta 2$ and 3 , ITG B1 and B3, COL 3A1 and 1A2, and MMP 1 and 9 (Additional file 3: Table S3 and Fig. 4a). In the Cell Motility array (Additional file 4: Table S4), 1 gene was upregulated in the gels of patient cells with TA-supplemented compared to patient cells with vehicle media, and 20 were down-regulated (Fig. 4b).

\section{Quantitative real-time PCR}

To confirm the microarray data, select genes that expressed twofold or greater changes in the arrays and were related to the TGF- $\beta$ signaling were analyzed with quantitative Real-Time PCR (RT-PCR). All gene expressions were consistent with array results. In the comparison of patient and control cells in vehicle media, TGF- $\beta 1$, COL1A2 and COL3A1 were all significantly upregulated, and VEGFA was down-regulated (Fig. 5a). Similarly, patient cells treated with TA all showed significant decreases in TGF- $\beta 1$, COL1A2, COL3A1 and VEGFA as was found in the arrays (Fig. 5b).

Collagen degradation assessment by immunoassay (ELISA) No significant difference in collagen fragment concentration was observed between treatment types or cell types, or in individual group comparisons.

\section{Discussion}

CTS is typified by non-inflammatory SSCT fibrosis with median nerve compression $[8,9]$. Surgical decompression is the most effective therapy, but steroid injection has been the main non-operative therapy. TA and other anti-inflammatory steroids are used to treat orthopedic conditions such as tendinopathy, neuropathy, repetitive 
Table 2 Summary of the analysis of the main effects on mechanical testing

\begin{tabular}{|c|c|c|c|c|}
\hline Outcome & Factor & Level & Mean (SD) & $p$-value \\
\hline \multirow[t]{4}{*}{ Decay Time Constant (days-1) } & \multirow[t]{2}{*}{ Treatment Type } & TA & $2.9(1.0)$ & \multirow[t]{2}{*}{$<0.001^{*}$} \\
\hline & & No TA & $2.2(0.7)$ & \\
\hline & \multirow[t]{2}{*}{ Cell Type } & Cadaver (control) & $2.5(1.1)$ & \multirow[t]{2}{*}{$<0.001^{*}$} \\
\hline & & CTS patient & $2.6(0.7)$ & \\
\hline \multirow[t]{4}{*}{ Tensile Strength (mN) } & \multirow[t]{2}{*}{ Treatment Type } & TA & $7.0(1.2)$ & \multirow[t]{2}{*}{$<0.001^{*}$} \\
\hline & & No TA & $5.8(1.3)$ & \\
\hline & \multirow[t]{2}{*}{ Cell Type } & Cadaver (control) & $6.6(1.4)$ & \multirow[t]{2}{*}{0.921} \\
\hline & & CTS patient & $6.1(1.3)$ & \\
\hline \multirow[t]{4}{*}{ Stiffness $(\mathrm{mN} / \mathrm{mm})$} & \multirow[t]{2}{*}{ Treatment Type } & TA & $1.1(0.4)$ & \multirow[t]{2}{*}{$<0.001^{*}$} \\
\hline & & No TA & $0.7(0.3)$ & \\
\hline & \multirow[t]{2}{*}{ Cell Type } & Cadaver (control) & $0.8(0.3)$ & \multirow[t]{2}{*}{$0.004^{*}$} \\
\hline & & CTS patient & $1.0(0.4)$ & \\
\hline
\end{tabular}

$*$ Statistically significant

motion injuries and inflammatory symptoms and reduce pain, inflammation and limitations in mobility [23, 24]. However, the mechanism of steroid therapy is not yet completely understood. Cell-seeded gel contraction-the transformation of a collagen lattice caused by cellular action-is a useful quantitative model and has been used to study fibroblast proliferation and reorganization of structural proteins in the extracellular matrix (ECM) and the effects of TGF- $\beta$ signaling on these processes $[25,26]$. In this study, we sought to characterize changes in both SSCT fibroblast behavior and fibroblasts' interaction with collagen seeded with cells from normal tissue and idiopathic CTS tissue individually, with and without TA treatment, to investigate the effect of steroid treatment on SSCT fibroblast gene expression and function in a gel ring contraction model.

The results of the mechanical property test of gels with vehicle media (Fig. 2) support those of our previous study comparing patient and control cells, although the difference in tensile strength was not significant [19]. Regarding TA treatment, the effect of blurring the margins was greater in gels seeded with patient cells (Fig. 1), suggesting that TA had a greater effect on these cells and may have impeded their ability to contract the gel. While the mechanism of action of TA when injected to treat CTS is unknown, this finding suggests that TA may somehow interfere with the progress of synovial fibrosis that is commonly seen in CTS patients. Additionally, TA treatment significantly increased gel contraction rate, tensile strength and stiffness in control cells but only stiffness in patient cells (Fig. 2), suggesting that TA has a different effect in normal and CTS-affected cells. Specifically, TA treatment seems to involve impeding collagen synthesis and reorganizing molecular cross-linking in collagen, resulting in increased tissue stiffness and tensile strength, which is consistent with previous studies [17, 27, 28].

In this study, the changes in fibrotic and ECM gene expression in gels seeded with patient cells compared to

Table 3 Summary of analysis of the effect of TA, separately by gel type

\begin{tabular}{|c|c|c|c|c|}
\hline Outcome & Cell Type & TA & Mean (SD) & $p$-value \\
\hline \multirow[t]{4}{*}{ Decay Time Constant $\left(\right.$ days $\left.^{-1}\right)$} & Cadaver (control) & No TA & $1.9(0.8)$ & $<0.001^{*}$ \\
\hline & & TA & $3.0(1.2)$ & \\
\hline & CTS patient & No TA & $2.5(0.6)$ & 0.225 \\
\hline & & TA & $2.7(0.8)$ & \\
\hline \multirow[t]{4}{*}{ Tensile Strength (mN) } & Cadaver (control) & No TA & $5.8(1.3)$ & $<0.001^{*}$ \\
\hline & & TA & $7.4(1.0)$ & \\
\hline & CTS patient & No TA & $5.8(1.4)$ & 0.157 \\
\hline & & TA & $6.5(1.2)$ & \\
\hline \multirow[t]{4}{*}{ Stiffness $(\mathrm{mN} / \mathrm{mm})$} & Cadaver (control) & No TA & $0.6(0.1)$ & $<0.001^{*}$ \\
\hline & & TA & $1.0(0.3)$ & \\
\hline & CTS patient & No TA & $0.9(0.3)$ & $0.042^{*}$ \\
\hline & & TA & $1.2(0.4)$ & \\
\hline
\end{tabular}



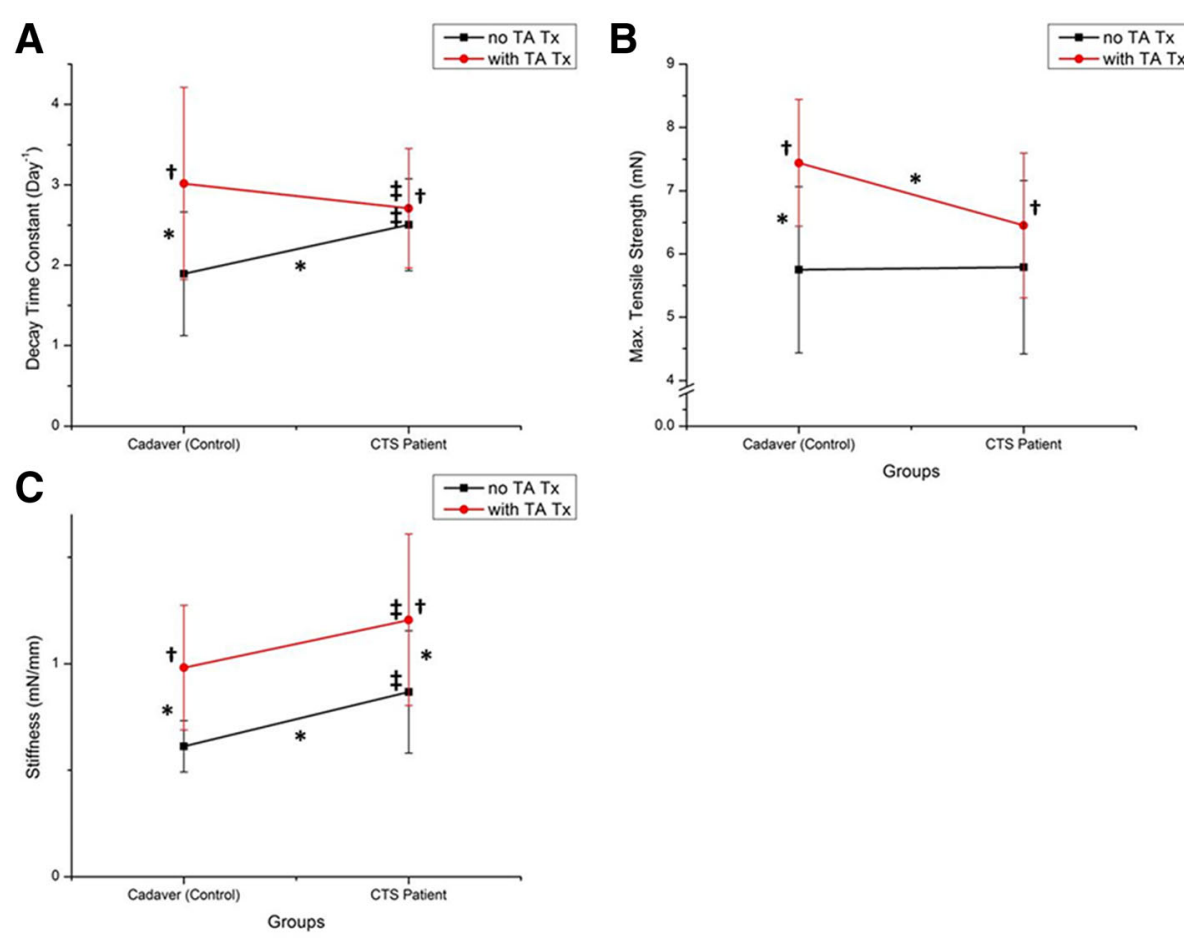

Fig. 2 a Decay time constant means, b Tensile strength means and $\mathbf{c}$ Stiffness means for the cell type and treatment type. Bars denote mean \pm SD. Two-way ANOVA showed significant effects of cell type and treatment type. $t p<0.05$, TA treatment overall compared with vehicle control; $\neq p<0.05$, patient overall compared with control; ${ }^{*} p<0.05$, significant difference between groups in individual factors

those seeded with control cells (Fig. 3) were consistent with those in previous studies, indicating that fibrotic pathways are important mediators in this model and supporting the common histopathological observation that the fibrosis seen in CTS is not associated with inflammation $[8,9,21]$.

Regarding TA treatment of gels seeded with patient cells (Fig. 4), TA inhibited the expression of TGF- $\beta$-related fibrotic and ECM genes, such as collagens, TGF- $\beta$ s and MMPs, and promoted expression of remodeling proteinase genes, including TIMP and thrombospondin. These results were consistent with those of previous studies, which showed that TA modulates TGF- $\beta$ 's transcription and translation and in turn ECM composition $[27,29]$. One mechanism of action is the steroids' inhibition of MMP transcription, which may negatively impact collagen synthesis by suppressing protein binding activity [30, 31]. In this study, some integrins (Additional file 1: Table S1), such as ITGB1 and ITGB3, were upregulated in the gels of patient cells with vehicle media compared to those of control cells with vehicle media, although the change was less than twofold. However, in the patient cells with TA treatment, integrins were down-regulated twofold compared to those with vehicle
A

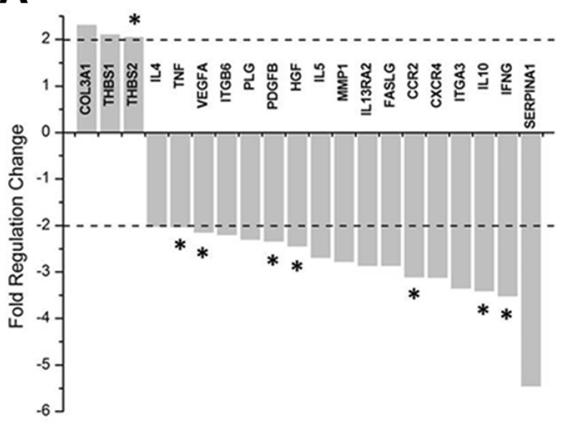

B

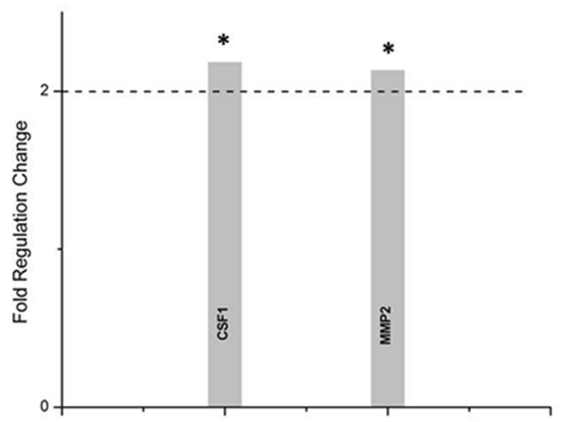

Fig. 3 a Human fibrosis array and $\mathbf{b}$ Cell motility array relative fold change in genes from the patient group without TA treatment compared to the control group without TA treatment. (* indicates significant differences, $p<0.05$ ) 
A

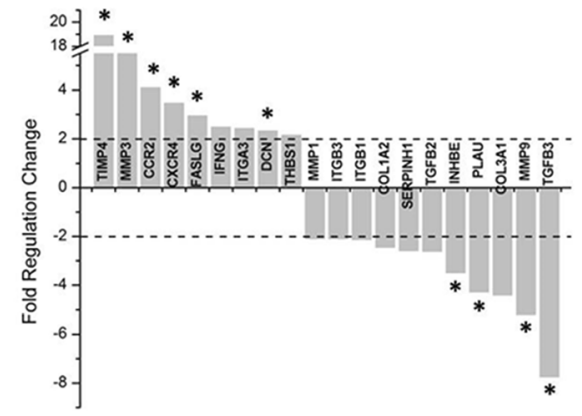

B

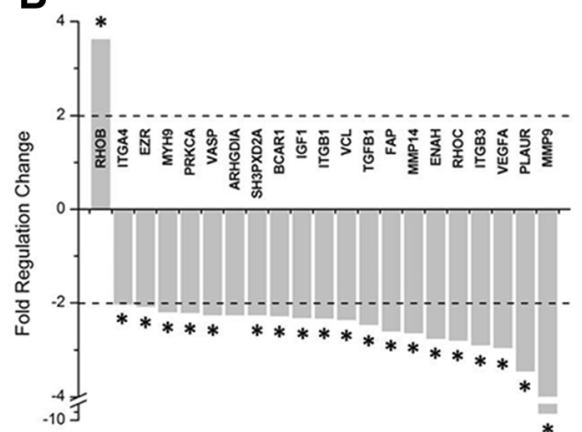

Fig. 4 a Human fibrosis array and $\mathbf{b}$ Cell motility array relative fold change in genes from the patient group with TA treatment compared to the patient group without TA treatment. (* indicates significant differences, $p<0.05$ )

media (Fig. 4). These results are consistent with those of previous studies, in which dexamethasone treatment of human-derived tendon cells decreased $\beta 1$-integrin synthesis and reduced type I collagen production [32]. Integrins mediate translational signaling from the adjacent ECM to change cell behaviors such as adhesion, migration and proliferation to modulate cell-ECM and cell-cell adhesion, resulting in fibrosis [32, 33]. Integrins can regulate canonical and non-canonical TGF- $\beta$ fibrotic signaling processes (such as systemic sclerosis, pulmonary fibrosis and cancer). Additionally, TGF- $\beta$ regulates integrins to modulate cell behaviors, such as migration and adhesion [34, 35]. The cytokines VEGF and PDGF are additional known mediators of fibrosis both separately and in conjunction with TGF- $\beta$. However, in our study, PDGF and VEGF expressions were suppressed in the patient groups regardless of treatment type (Figs. 3 and 4). Thus, TA does not seem to affect these pro-fibrotic pathways. Reducing fibrosis via these other pathways may be a promising avenue for further research into medical treatments of CTS.
To understand how the untreated and TA-treated fibroblasts modulate and regulate the adjacent ECM in our gel contraction model, we examined whether collagen breakdown was a mechanism involved in the gel contraction in both control and treated conditions. Many studies have demonstrated that collagen breakdown is normally a part of tissue regeneration and that corticosteroids inhibit the degradation of mature collagen by suppressing the collagen breakdown [36, 37]. There was no significant difference in the products of collagen breakdown between gel types or treatment types, indicating that collagen breakdown is not the likely mechanism of this cell-seeded gel contraction model.

There are some limitations in this study. First, despite the gender and age match between the patient and control cells, the sample size was small. However, we were able to see significant cell and treatment interactions. Second, the phenomenon of the rough edge (margin) of contracted gel was found in all TA treatment groups regardless of cell type. In order to quantify and compare the rough edge we measured a solidly visible edge as the
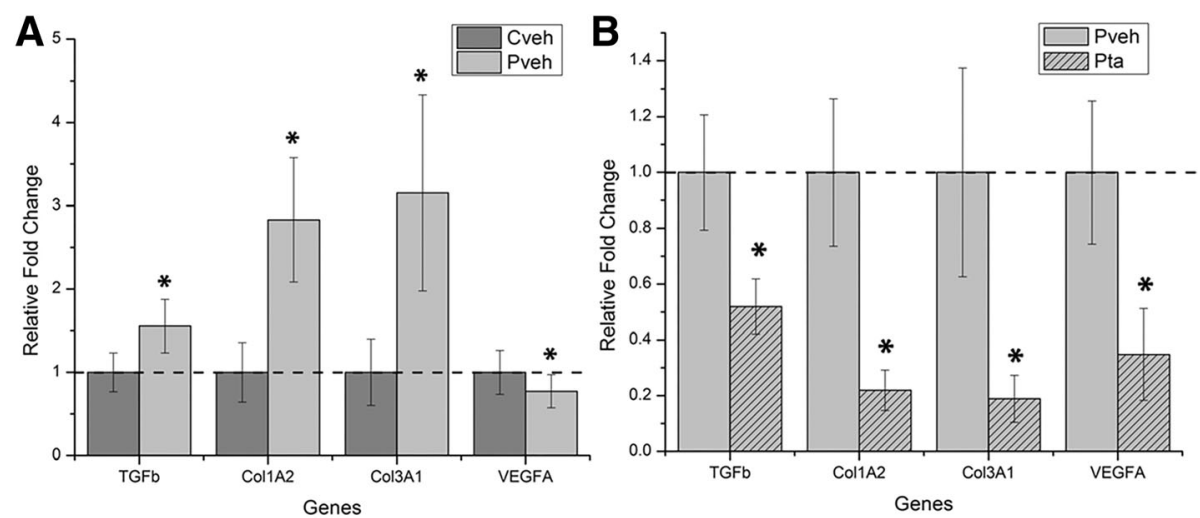

Fig. 5 Confirmation of the arrays' gene expressions was analyzed by quantitative RT-PCR between a the untreated patient group (Cveh) and the untreated control group (Pveh) (results are normalized to the untreated control group); $\mathbf{b}$ the treated patient group (Pta) and the untreated patient group (results are normalized to the untreated patient group). (* indicates significant differences, $p<0.05$ ) 
contraction edge to quantify the contraction rate. Third, we investigated only canonical TGF- $\beta$ fibrotic signaling processes. In the future, we plan to investigate and compare the quality and arrangement, and the changes of inter-/intra-collagen fibers after contraction between treated and non-treated groups using confocal microscope and scanning electron microscope respectively. Moreover, we plan to study other possible signaling processes related to fibrosis. However, researchers may be able to use the current model to understand the dynamics of SSCT pathogenesis and treatment more clearly find ways to block signaling pathways or test new therapies.

\section{Conclusion}

In conclusion, our results in collagen gel contraction were consistent with those of previous studies: there was an increased cell-seeded gel contraction rate, stiffness and tensile strength in gels with media of patient cells compared to those of control cells. We also found that the TA-treated groups had poorly defined margins after contraction in both cell types (though this was more pronounced in the patient groups), which suggests that TA affected gel structural integrity. Fibrotic genes and ECM regulators, such as TGF- $\beta$, collagens and integrins, were upregulated in the gels of patient cells with vehicle media compared to the gels of control cells with vehicle media. Additionally, in gels with TA-supplemented cells, the patient cell groups had increased expression of remodeling proteinases compared to the control cell groups, indicating that TA modulates TGF- $\beta$ signaling and affects ECM composition. Furthermore, with TA treatment, patient cells' fibrotic genes and ECM regulators, such as TGF- $\beta$, collagens and integrins, were down-regulated, indicating that TA may be working in part by decreasing an overall fibrotic gene expression. This study shows that steroids affect cell regulation on gel structural integrity and regulate fibrotic gene expression in patient cells and may affect CTS by modulating cellular function. This may explain the reported decreases in CTS symptoms for some patients treated with steroids. Further study of these identified genes and pathways may help researchers discover new and more effective therapeutic targets for CTS treatment.

\section{Additional files}

Additional file 1: Table S1. Gene fold changes of the CTS group without TA treatment compared to the control group without TA treatment in Human Fibrosis Array (XLS $84 \mathrm{~kb}$ )

Additional file 2: Table S2. Gene fold changes of the CTS group without TA treatment compared to the control group without TA treatment in Cell Motility Array. (XLS $84 \mathrm{~kb}$ )

Additional file 3: Table S3. Gene fold changes of the CTS group with TA treatment compared to the CTS group without TA treatment in Human fibrosis array. (XLS $84 \mathrm{~kb})$
Additional file 4: Table S4. Gene fold changes of the CTS group with TA treatment compared to the CTS group without TA treatment in Cell Motility Array. (XLS 84 kb)

Acknowledgements

No one else contributed towards the article except for the authors.

\section{Funding}

This study was supported by NIH/NIAMSAR49823, NIH/NIAMS F32 AR063596 and a 2013 American Society for Surgery of the Hand Basic Science Grant.

\section{Availability of data and materials}

Data will be shared upon reasonable request. Please contact:

Peter C. Amadio, MD

Mayo Clinic

200 First St SW

Rochester

MN 55905

pamadio@mayo.edu

\section{Authors' contributions}

Substantial contributions to research design, or the acquisition, analysis or interpretation of data: THY; AG; ART; DRL; CZ; PCA; Drafting the paper or revising it critically: THY; AG; DRL; PCA. All authors read and approved the final manuscript.

\section{Ethics approval and consent to participate}

Cadaver were obtained from (and returned to) Mayo Clinic's Willed Body Program. The Mayo Clinic Institutional Review Board deemed the use of cadaver tissue to be IRB exempt. Patients were recruited through Mayo Clinic Institutional Review Board approved study 1056-02. Preoperative written consent was obtained from each subject.

Consent for publication

Not applicable.

\section{Competing interests}

Authors Anne Gingery and Andrew Thoreson are editorial board members of BMC Musculoskeletal Disorders.

\section{Publisher's Note}

Springer Nature remains neutral with regard to jurisdictional claims in published maps and institutional affiliations.

\section{Author details}

${ }^{1}$ Biomechanics \& Tendon and Soft Tissue Biology Laboratory, Division of Orthopedic Research, Rochester, USA. ${ }^{2}$ Division of Biomedical Statistics and Informatics, Department of Health Science Research, Mayo Clinic, Rochester, MN 55905, USA. ${ }^{3}$ Tendon and Soft Tissue Biology Laboratory, Division of Orthopedic Research, Mayo Clinic, 200 First Street SW, Rochester, MN 55905, USA.

Received: 7 February 2018 Accepted: 13 September 2018

Published online: 22 September 2018

\section{References}

1. Gelfman R, Melton LJ 3rd, Yawn BP, Wollan PC, Amadio PC, Stevens JC. Long-term trends in carpal tunnel syndrome. Neurology. 2009;72(1):33-41.

2. Palmer DH, Hanrahan LP. Social and economic costs of carpal tunnel surgery. Instr Course Lect. 1995:44:167-72.

3. Atroshi I, Gummesson C, Johnssson R, Ornstein E, Ranstam J, Rosen I. Prevalence of carpal tunnel syndrome in a general population. JAMA. 1999; 282(2):153-8.

4. Szabo RM, Madison M. Carpal tunnel syndrome. Orthop Clin North Am. 1992;23(1):103-9.

5. Armstrong TJ. Ergonomics and cumulative trauma disorders. Hand Clin. 1986;2(3):553-65.

6. Blanc PD, Faucett J, Kennedy JJ, Cisternas M, Yelin E. Self-reported carpal tunnel syndrome: predictors of work disability from the National Health 
Interview Survey Occupational Health Supplement. Am J Ind Med. 1996; 30(3):362-8.

7. Leclerc A, Franchi P, Cristofari MF, Delemotte B, Mereau P, Teyssier-Cotte C, Touranchet A. Carpal tunnel syndrome and work organisation in repetitive work: a cross sectional study in France. Study group on repetitive work. Occup Environ Med. 1998;55(3):180-7.

8. Donato G, Galasso O, Valentino P, Conforti F, Zuccala V, Russo E, Maltese L, Perrotta I, Tripepi S, Amorosi A. Pathological findings in subsynovial connective tissue in idiopathic carpal tunnel syndrome. Clin Neuropathol. 2009;28(2):129-35.

9. Schuind F, Ventura M, Pasteels JL. Idiopathic carpal tunnel syndrome: histologic study of flexor tendon synovium. J Hand Surg Am. 1990;15(3): 497-503.

10. Zhao C, Ettema AM, Berglund $L$, An KN, Amadio PC. Gliding resistance of flexor tendon associated with carpal tunnel pressure: a biomechanical cadaver study. J Orthop Res. 2011;29(1):58-61.

11. Ettema AM, Zhao C, Amadio PC, O'Byrne MM, An KN. Gliding characteristics of flexor tendon and tenosynovium in carpal tunnel syndrome: a pilot study. Clin Anat. 2007;20(3):292-9.

12. Yoshii Y, Zhao C, Zhao KD, Zobitz ME, An KN, Amadio PC. The effect of wrist position on the relative motion of tendon, nerve, and subsynovial connective tissue within the carpal tunnel in a human cadaver model. J Orthop Res. 2008;26(8):1153-8.

13. Keith MW, Masear V, Chung KC, Amadio PC, Andary M, Barth RW, Maupin K, Graham B, Watters WC 3rd, Turkelson CM, et al. American Academy of Orthopaedic surgeons clinical practice guideline on the treatment of carpal tunnel syndrome. J Bone Joint Surg Am. 2010;92(1):218-9.

14. Plotkin MB, Foss ML, Goldin B, Ellis DG. Dose response effects of anti inflammatory steroid injections on mechanical properties of rat tail tendons. Med Sci Sports Exerc. 1976;8(4):230-4.

15. Zeisig E. Natural course in tennis elbow-lateral epicondylitis after all? Knee Surg Sport Tr A. 2012;20(12):2549-52.

16. Karadas O, Tok F, Akarsu S, Tekin L, Balaban B. Triamcinolone Acetonide vs procaine hydrochloride injection in the Management of Carpal Tunnel Syndrome: randomized placebo-controlled trial. J Rehabil Med. 2012:44(7):601-4.

17. Mackie JW, Goldin B, Foss ML, Cockrell JL. Mechanical properties of rabbit tendons after repeated antiinflammatory steroid injections. Med Sci Sports Exerc. 1974;6(3):198-202.

18. Cartwright MS, White DL, Demar S, Wiesler ER, Sarlikiotis T, Chloros GD, Yoon JS, Won SJ, Molnar JA, Defranzo AJ, et al. Median nerve changes following steroid injection for carpal tunnel syndrome. Muscle Nerve. 2011;44(1):25-9.

19. Yang T-H, Thoreson AR, Gingery A, An K-N, Larson DR, Zhao C, Amadio PC. Collagen gel contraction as a measure of fibroblast function in carpal tunnel syndrome. J Biomed Mater Res A. 2015;103(2):574-80.

20. Chen H-C, Yang T-H, Thoreson AR, Zhao C, Amadio PC, Sun Y-N, Su F-C, An K-N. Automatic and quantitative measurement of collagen gel contraction using model-guided segmentation. Meas Sci Technol. 2013;24(8):085702.

21. Gingery A, Yang TH, Passe SM, An KN, Zhao C, Amadio PC. TGF- $\beta$ signaling regulates fibrotic expression and activity in carpal tunnel syndrome. J Orthop Res. 2014;32(11):1444-50.

22. Hawse JR, Cicek M, Grygo SB, Bruinsma ES, Rajamannan NM, van Wijnen AJ, Lian JB, Stein GS, Oursler MJ, Subramaniam M, et al. TIEG1/KLF10 modulates Runx2 expression and activity in osteoblasts. PLoS One. 2011;6(4):e19429.

23. Hollander JL. Intra-articular hydrocortisone in arthritis and allied conditions; a summary of two years' clinical experience. J Bone Joint Surg Am. 1953;35-A(4):983-90.

24. Stephens MB, Beutler Al, O'Connor FG. Musculoskeletal injections: a review of the evidence. Am Fam Physician. 2008;78(8):971-6.

25. Chieh HF, Sun YL, Liao JD, Su FC, Zhao CF, Amadio PC, An KN. Effects of cell concentration and collagen concentration on contraction kinetics and mechanical properties in a bone marrow stromal cell-collagen construct. J Biomed Mater Res A. 2010;93A(3):1132-9.

26. Bell E, Ivarsson B, Merrill C. Production of a tissue-like structure by contraction of collagen lattices by human fibroblasts of different proliferative potential in vitro. Proc Natl Acad Sci U S A. 1979;76(3):1274-8.

27. McCoy BJ, Diegelmann RF, Cohen IK. In vitro inhibition of cell growth, collagen synthesis, and prolyl hydroxylase activity by triamcinolone acetonide. Proc Soc Exp Biol Med. 1980;163(2):216-22.
28. Vogel HG. Influence of age, treatment with corticosteroids and strain rate on mechanical properties of rat skin. Biochim Biophys Acta. 1972;286(1):79-83.

29. Carroll LA, Hanasono MM, Mikulec AA, Kita M, Koch RJ. Triamcinolone stimulates bFGF production and inhibits TGF- $\beta 1$ production by human dermal fibroblasts. Dermatol Sur. 2002;28(8):704-9.

30. Aljada A, Ghanim H, Mohanty P, Hofmeyer D, Tripathy D, Dandona P. Hydrocortisone suppresses intranuclear activator-protein-1 (AP-1) binding activity in mononuclear cells and plasma matrix metalloproteinase 2 and 9 (MMP-2 and MMP-9). J Clin Endocr Metab. 2001;86(12):5988-91.

31. LeBert DC, Squirrell JM, Rindy J, Broadbridge E, Lui Y, Zakrzewska A, Eliceiri KW, Meijer AH, Huttenlocher A. Matrix metalloproteinase 9 modulates collagen matrices and wound repair. Development. 2015;142(12):2136-46.

32. Sendzik J, Shakibaei M, Schafer-Korting M, Lode H, Stahlmann R. Synergistic effects of dexamethasone and quinolones on human-derived tendon cells. Int J Antimicrob Agents. 2010;35(4):366-74.

33. van der Flier A, Sonnenberg A. Function and interactions of integrins. Cell Tissue Res. 2001;305(3):285-98.

34. Margadant C, Sonnenberg A. Integrin-TGF-beta crosstalk in fibrosis, cancer and wound healing. EMBO Rep. 2010;11(2):97-105.

35. Henderson NC, Sheppard D. Integrin-mediated regulation of TGF $\beta$ in fibrosis. Biochim Biophys Acta. 2013;1832(7):891-6.

36. Nimni ME, Bavetta LA. Collagen synthesis and turnover in the growing rat under the influence of methyl prednisolone. Proc Soc Exp Biol Med. 1964; 117:618-23.

37. Koob TJ, Jeffrey JJ, Eisen AZ. Regulation of human skin collagenase activity by hydrocortisone and dexamethasone in organ culture. Biochem Biophys Res Commun. 1974;61(3):1083-8.
Ready to submit your research? Choose BMC and benefit from:

- fast, convenient online submission

- thorough peer review by experienced researchers in your field

- rapid publication on acceptance

- support for research data, including large and complex data types

- gold Open Access which fosters wider collaboration and increased citations

- maximum visibility for your research: over $100 \mathrm{M}$ website views per year

At $\mathrm{BMC}$, research is always in progress.

Learn more biomedcentral.com/submissions 